\title{
The Risk-Return binomial after rating changes
}

\author{
Pilar Abad \\ Universidad Rey Juan Carlos
}

M. Dolores Robles

Universidad Complutense de Madrid

\begin{abstract}
Risk-averse investors take into consideration risk-return tradeoff for decide their new position after the release of relevant information. This paper analyzes the informational content of rating change announcements focusing on the joint reaction they cause on the risk-return binomial. Our purpose is to identify the main factors that signal which announcements are informative. To do that we estimate a binomial logit model for the probability of informative content of credit rating announcements. We analyze a sample of rating events affecting Spanish listed firms from 2000 to 2010. Empirical results show significant differences in the informative content between positive and negative rating events. For both kinds of announcements, we find higher informative content when agencies agree about the new level of solvency, whereas those affecting high covered firm that operate in highly regulated sectors are the less informative. Other factors as the presence of a previous rating refinements or trends in the credit quality reveals different information depending on the direction of the rating event. Finally, we find the announcements after de crisis disclose less information, suggesting a loss of reputation of CRAs.
\end{abstract}

Keywords: Abnormal return, abnormal systematic risk, abnormal volatility, logit model

JL Classification G12, G14, G24, C22

\section{Working Paper no 1423 June, 2014}

UNIVERSIDAD

COMPLUTENSE

MADRID 


\title{
The Risk-Return binomial after rating changes
}

Pilar Abad, Universidad Rey Juan Carlos (pilar.abad@urjc.es)

M. Dolores Robles, Universidad Complutense de Madrid (mdrobles@ccee.ucm.es)

June 2014

\begin{abstract}
.
Risk-averse investors take into consideration risk-return tradeoff for decide their new position after the release of relevant information. This paper analyzes the informational content of rating change announcements focusing on the joint reaction they cause on the risk-return binomial. Our purpose is to identify the main factors that signal which announcements are informative. To do that we estimate a binomial logit model for the probability of informative content of credit rating announcements. We analyze a sample of rating events affecting Spanish listed firms from 2000 to 2010. Empirical results show significant differences in the informative content between positive and negative rating events. For both kinds of announcements, we find higher informative content when agencies agree about the new level of solvency, whereas those affecting high covered firm that operate in highly regulated sectors are the less informative. Other factors as the presence of a previous rating refinements or trends in the credit quality reveals different information depending on the direction of the rating event. Finally, we find the announcements after de crisis disclose less information, suggesting a loss of reputation of CRAs.
\end{abstract}

JEL Classification: G12, G14, G24, C22

Key words: Abnormal return, abnormal systematic risk, abnormal volatility, logit model

\section{Acknowledgements:}

The information provided by Fitch and Moody's is appreciated. Any errors are solely the responsibility of the authors. This work has been funded by the Spanish Ministerio de Ciencia y Tecnología (ECO2012-31941 and ECO2011-23959), and Junta de Comunidades de Castilla-La Mancha (PEII110031). 


\section{Introduction}

The analysis of credit rating agencies (CRAs) and their role on financial markets is crucial nowadays, when their central role in the current financial crisis has put them in the eye of the storm. Credit rating may act as a mechanism for addressing the considerable degree of information asymmetry in the financial markets. The information content hypothesis ( $\mathrm{ICH})$ states that rating agencies handle confidential data and therefore, rating revisions reveal new information to the market. Under the efficient market paradigm, this new information must be rapidly included into prices. However, credit ratings can be valuable to investors although they do not contain valuable information, due to the regulatory privileges that they provide (Weber and Darbellay, 2008; Bongaerts, Cremers and Goetzmann, 2012).

A number of studies have analyzed ICH, most of which focusing on the stock market. The main conclusion is that returns are influenced by bond rating changes, especially by downgrades (e.g., Matolcy and Lianto, 1995; Barron, Clare and Thomas, 1997; Elayan, Hsu and Meyer, 2001; Abad and Robles, 2006, 2007; Purda, 2007 or Jorion and Zhang, 2007). Few studies show evidence concerning the effects of rating changes on issuer's risks (Impson, Karafiath and Glascock, 1992; Chandra and Nayar, 1998; Barron et al., 1997; Abad and Robles, 2006, 2014; Hubler, Louargant, Ory and Raimbourg, 2013). In both cases, the results demonstrate the importance of rating change announcements in revealing specific information that is relevant to price formation.

This literature establishes the expected effect of rating changes on returns and on beta risk individually, disregarding the joint reaction of the risk-return binomial. 
However, under the hypothesis that investor are risk-averse, there is a risk-return tradeoff that may be taken into account in order to determine the information content of rating events. Our main objective is to fill in that gap by analyzing the ICH considering the combined response of expected returns and both risks to different rating actions announced by CRAs. We focus on finding the main factors to signal which announcements are informative. Instead the traditional event-study plus a cross sectional analysis usual in the literature, we examine the impact on the probability that a rating announcement convey new information. As the informational content of these credit announcements is largely unobservable, we use the fact that the abnormal behavior of risk and returns around the announcement date should be significant. We estimate a logit model that relates the likelihood of occurrence or non-occurrence of an informative credit rating announcement to a vector of explanatory variables. We focus on the characteristics of the returns, the volatility, the rating change, the agency, the issuer and the economic environment as explanatory variables or factors that determine these probabilities. We also analyze the effect of the ongoing financial crisis.

We analyze the rating announcement of Spanish companies listed on the Electronic Continuous Stock Market from 2000 to 2010. The Spanish stock exchange is a medium-sized market that plays a relevant role among the different stock exchanges in Europe. According to the International Federation of Stock Exchanges (IFSE), the relative size of the Spanish Stock Exchange in terms of market capitalization is approximately $10 \%$ of the size of the NYSE in 2010. We use rating announcement by the "Big Three" rating agencies. 
Our study makes a number of relevant contributions. First, instead of an aggregate analysis based on a traditional two-step event study, we propose a binomial logistic model to analyze the relationship between rating announcement and the risk/returns binomial. Second, we characterize the main factors that determine the simultaneous response in returns and risk. Third, we explore the incidence of the current financial turmoil.

Our main findings can be summarized as follows. First, we find different effects of improvements and deteriorations announcements on informational contained. Interestingly, there are more characteristics relevant regard the ICH in the improvements announcement than deteriorations. Second, the main attributes of rating events relevant to explain the response of systematic risk differs from those relevant to explain the response of returns. Finally, our results suggest a loss of reputation of CRAs in the later financial turmoil. After the crisis beginning, positive and negative credit rating announcement disclose less relevant information. The relevance of this analyze is twofold. First, it helps to fills a gap in the literature on the relationship between rating actions and returns and beta risk. Second, our results can help market participants to make effective investment decisions based on the risk-return profile. The investor can identify the main factors in the rating announcement and know how risk-return binomial change.

The paper is structured as follows. Section 2 presents the main hypothesis regarding the factors that determine the informational announcement. Section 3 shows the methodology. Section 4 describes the data set. Section 5 the main results and Section 6 concludes. 


\section{Main Hypothesis to test}

In order to identify rating changes as a major source of credit news, market participants must check whether an announcement contains new information or whether credit news is already fully incorporated into prices. We assume that in the latter case the impact of the announcement is going to be zero whereas in the former there will be some abnormal reaction.

Our main hypothesis is that this informative content depends on several attributes. We select different factors that have been hypothesized by literature to determine the market reaction to rating changes. First, we focus on the rating refinements: outlooks and reviews. These refinements are introduced by CRAs in response to critics on their failure for timely rating changes. Altman and Rijken (2007) state that rating refinements help to transfer relevant information about the issuers' default risk allowing agencies to strike a balance between rating timeliness and rating stability. In this line, we expect reviews and outlook reports include relevant information as effective rating changes do.

In addition, some authors have found differences in rating actions across the three main CRAs. Morgan (2002) shows that Moody's is more conservative than S\&P when a split occurs. Grande and Parsley (2005) and Norden and Weber (2004) find that $\mathrm{S} \& \mathrm{P}$ tends to provide the earliest and the most thorough market assessment. Livingston, Wei and Zhou (2010) find Moody's ratings arouse greater market reactions compared to S\&P. Conversely, Guettler and Wahrenburg (2007) find that bond ratings by Moody's and Standard \& Poor's are highly correlated, pointing to no differences among agencies. In the case of Spain, Moody's and S\&P began to operate in 1993 and 
Fitch in 1995, but Moody's has the dominant position, with $41.4 \%$ of rating actions in our sample. ${ }^{1}$ We hypothesize that market gives more credibility to the leading agency, due to its expertise that increase the informative content of its rating announcements with respect the other CRAs.

Other attributes that may signal the information content of rating events are too related to the agencies. Commonly, issues and issuers can be rated by one, two or more agencies simultaneously (multi-rating). ${ }^{2}$ Multirating increases competence among CRAs, and incentive agencies to be more active monitors for certain issuers. This monitor activity increases the visibility of the firm to market participants and allows investors to anticipate the relevant information before the announcement, making them less informative. Our hypothesis, in this context, is that rating actions affecting widely covered issues - i.e rated by a higher number of CRAs or with a higher number of announcements about their debt- have lower novel information than those affecting barely covered issues.

\footnotetext{
${ }^{1}$ There are scarce differences between rating actions by Moody's and Standard and Poor's in our sample in terms of the prior rating and the number of notches the rating changes. We only find small differences in the size of the jump looking at upgrades and downgrades separately, proving Moody's slightly more optimistic.

${ }^{2}$ Literature has studied different feature of multirating. We find studies that focus on the relation between quality of the rating and the number of ratings. Becker and Milbourn (2011) find that quality is inversely related to the number of active rating agencies. Conversely, Peña-Cerezo, RodríguezCastellanos and Ibáñez-Hernández (2013) find that increasing the number of CRAs that rate securitization issues increase reliability in the rating achieved by each issue. Xia (2014) finds that the introduction of a new agency increases the quality of ratings.
} 
On the other hand, multirating frequently underscores differences of opinion across the rating agencies. These split ratings seems to be related to differences in the methodology or in the weight that CRAs gives to relevant information (Cantor and Paker, 1997). It could be expected that disagreements among agencies about the solvency of a firm could increase the level of asymmetric information in the market. Hence, we hypothesize that the amount of information provided by a rating event depends on whether it presents the same opinion about the firm's default risk as the other agencies.

Some other attributes may cause differences in the attention that market plays to rating actions. For example, it is likely that the market does not immediately detect when a company's solvency begins to change. If a continuous decrease (improvement) in solvency occurs, agencies will carry out a series of successive downgrade (upgrade) announcements regarding the rating of the issuer's debt. In this situation, it is expected that the informational content of each successive rating action will be lower than the previous one. As such, our hypothesis is that events included in an issuer's solvency trend would be less informative.

Additionally, we hypothesize that expected rating events as effective rating changes that are the resolution of credit watch procedures, will be less informative. Watch listing increases the firm's visibility and the market expectations of a rating change. Conversely, Boot et al. (2006) indicate that reviews probably increase the information content of effective changes because it discloses more confidential information. Credit watches allow issuers to improve solvency conditions avoiding 
rating cuts. According to this, the informational content of effective rating changes could vary depending on the presence of a previous refinement.

Similarly, credit rating agencies assign ratings to corporate issuers, long and short term debt, as well as to specific issues, such as notes, and structured finance instruments. Sometimes, rating announcements only refers to one of these concepts but frequently the rating action refers to several concepts at the same time (multiple rating changes). One may expect that the latter case (i.e. when the rating of several concepts change simultaneously) be motivated by a greater change in the solvency of the issuer. In this sense, we expect that these multiple rating changes be more informative. We also consider the possibility that the relevance of this information depends on the concept. In particular, issue ratings refer to the creditworthiness of a firm with respect to a specific financial obligation, and issuer credit ratings refers to its overall creditworthiness to pay its financial obligations. Our hypothesis is that announcement about changes in the second would be more informative as issuer rating measure the capacity and willingness of firms to meet its financial commitments as a whole.

The characteristics of investors may also indicate when rating actions reveal novel information. Jorion and Zhang (2007) find that the prior rating is the most important factor explaining the stock returns' reaction to rating changes. Abad and Robles (2014) also find that this factor is relevant to explain the response of beta risk. These effects could be related to constraint clauses faced by institutional investors that 
force them to make decisions based on the observed rating level ${ }^{3}$ and concentrate their activity mainly in the investment-grade level. ${ }^{4}$ In this context, we expect to find differences in the informative content of events that depend on the prior rating. These institutional rigidities can also result in stronger reaction to rating changes that cross the investment-grade frontier.

Furthermore, we can understand the number of notches the rating change as the degree of variation in credit quality of the issuer perceived by the agency. Our hypothesis is that bigger sizes of jump are directly related to the information about issuer solvency that the announcement reveals. Nevertheless, rating users are investors while agency revenues are paid by the rated firms. As Covitz and Harrison (2003) point out, this situation underscores a conflict of interest. Agencies may act in favor of issuers by delaying the release of downgrades and giving the issuer time to correct its credit quality. We expect that market participants could anticipate the information in the case of firms suffering a large change in their default risk. In this situation the delay of the agency could be greater. Agencies may require extra time in the case of large improvements because of the possible loss of reputation related with the bankruptcy of a highly rated business. ${ }^{5}$ In this case, we can find a negative relation between the informative content and the degree to which the rating is changed.

\footnotetext{
3 For example, pension funds are often allowed to deal only with investment-grade issues. Similarly, certain markets, such as the Eurobond market, may simply require the presence of a particular minimum rating before listing the debt issue.

${ }^{4}$ Most of bonds in our sample are in the investment grade with only 13 in the speculative grade.

${ }^{5}$ Recall the fall of Enron in 2001 or that of Lehman Brothers in 2008 for example.
} 
Several characteristics of the re-rated firms have been studied as relevant factors to explain the market reaction to rating events. Differences in the regulation affecting firms can lead on differences in the information content of rating changes (Schweitzer, Szewczyk and Varma, 1992). For highly regulated sectors, such as financial or energy sectors, there is probably more public information. In addition, these entities are in most cases supported in some extent by the state. ${ }^{6} \mathrm{~A}$ big proportion of issuers in our sample are financial enterprises, mainly commercial banks. The well-known "too-bigto-fail" paradigm suggests that regulators might intervene to avoid the default of large banks because of serious, adverse effects on the financial system. ${ }^{7}$ In this context, market participants may be insensitive to rating actions affecting systemic banks. This hypothesis implies lower useful information on rating changes affecting firms in highly regulated sectors than in other sectors.

Finally, the sample period we analyze covers the recent economic recession, originated by the housing bubble burst in September 2007 and reinforced in 2008 after the Lehman Brothers default. This period has been characterized by a more uncertain informational environment and high levels of volatility. Several authors find significant differences in rating action effects due to the crisis. For example, Jorion, Liu and Shi

\footnotetext{
${ }^{6}$ For example, in Spain, power prices are regulated and the state bore the liability for the gap between regulated power prices and higher generation costs.

${ }^{7}$ Major financial firms are assumed to be "too big to fail". Lehman Brothers was allowed to fail on September 15, 2008. However, numerous interventions by governments or central banks have taken place since then to avoid banks defaults. Several examples include Fortis (Belgium, Netherland and Luxemburg, 2008), Dexia (France and Belgium, 2008), Bradford \& Bingley (United Kingdom, 2008) and Caja Madrid (Spain, 2010).
} 
(2005) find less negative effects of downgrades on stock returns during the 2001 stock market crisis, and May (2010) finds a more negative reaction to downgrades in the US corporate bond market after 2007. We expect this increased uncertainty after the crisis began to cause higher levels of informational asymmetries, leading to higher information content of rating actions. Another important effect of the financial turmoil is the loss of rating agencies' credibility due to their central role in the sub-prime mortgage crisis or their failure to predict the Lehman Brothers default in $2008 .^{8}$ This loss of reputation should undermine the reliability of rating actions after the crisis.

\section{Modeling and testing strategy}

We are interested in analyze if several attributes of rating actions are the underlying determinants of the existence of valuable information in the rating announcement to explain the risk-return binomial of the re-rated firm. To do so, we analyze the probability that these rating announcements reveal relevant information. As their informational content is largely unobservable, we use as proxy a dummy variable that is equal to one when we observe a significant movement in risk-return binomial in the expected direction and zero otherwise. Then, we model a binomial logit model (BLM) that relates the likelihood of occurrence or non-occurrence of an informative credit rating action to a vector of explanatory variables. BLM is a popular approach to estimate the probabilities associated with events captured in a

\footnotetext{
8 See Crouchy et al. (2008) for an analysis of the role played by rating agencies in the subprime mortgage crisis.
} 
dichotomous variable. The probability of new information in the rating announcement is given by

$$
\operatorname{Pr}\left(y_{t}=1\right)=\frac{\exp \left(\tilde{x}_{t}^{\prime} \beta\right)}{1+\exp \left(\tilde{x}_{t}^{\prime} \beta\right)}
$$

where the vector $\tilde{x}_{t}^{\prime}$ includes the explanatory variables plus a constant and $\beta$ is a vector of coefficients. When $\beta_{\mathrm{i}}$ is significant, then the variable $\mathrm{x}_{\mathrm{i}}$ has an effect upon the probability of informative rating announcement. The model is estimated using maximum likelihood and goodness-of-fit is measured using the pseudo-R2 approach of McFadden (1974) and the percentage of accurate predictions by the model. Additionally, we compute the average partial effects - the average of the effect of an unit change of one independent variable on the probability, given that all other variables are constant- to assess the economic significance of this change. ${ }^{9}$

We consider several explanatory variables that allow testing the hypothesis described in Section 2. We focus on the characteristics of the returns, the volatility, the rating change, the agency, the issuer and the economic environment as explanatory variables or factors that determine these probabilities. In particular, to distinguish between effective rating changes and rating refinements we define two dummy variables, Review and Outlook report, equal to one if the rating action is a watchlisting or an outlook review respectively and zero otherwise.

\footnotetext{
${ }^{9}$ Average marginal effect is the average (over all observation) of partial derivatives of probabilities with respect to the vector of independent variables.
} 
To analyze the relevance of the agency, we define other two dummy variables, Moody's and SEP , equal to one if the rating action is announced by Moody's or S\&P respectively and zero otherwise.

To study the incidence of multi-rating we include several variables. First, the variables, Two agencies and Three agencies, that take the value of 1 if the issuer is rated by two or three CRAs respectively. Second, we include other two variables that may also proxy the degree of visibility of the firm. Highly covered (Barely covered) is a dummy variable equal to one if the issuer is in the first (fourth) quartile of issuer ranking with regards to the number of rating actions in the sample.

With respect to the agreement or disagreement among agencies, we include three variables: Simultaneous, that is a dummy variable equal to one if the rating action has been announced by two or more agencies the same day and zero otherwise, Split-rating, that is a dummy variable equal to one if the rating action follows an action by other agency in the opposite direction in the preceding 3 months and zero otherwise, and Second mover, that is a dummy variable equal to one if the rating action follows an action by other agency in the same direction in the preceding 3 months and zero otherwise.

We also include in the model variables that proxy whether a rating action is expected by the market or whether is a surprise. Trend rating is a dummy variable equal to one if the rating action has been preceded by one rating announcements in the same direction over the past 24 months and zero otherwise. Break trend is a dummy variable equal to one if the rating action has been preceded by two rating announcements in the opposite direction and zero otherwise. We also include the 
variable Expected, that is equal to one if the rating action has been preceded by a watchlisting or review and zero otherwise.

We proxy the "intensity" of the change in the solvency of the firm considering whether the rating refers to different concepts or not and the type of concepts affected. We define Multiple as a dummy variable equal to one if the rating action refers to several concepts at the same time, and the variable Issuer, as a dummy variable equal to one if the rating event refers to the issuer credit rating.

To consider differences related to the rating grade we include in the model the variables: Prior rating, that is a variable encoding the grades of the previous rating before the announcement, assigning value 1 to $\mathrm{AAA} / \mathrm{Aaa}, 2$ to $\mathrm{AA} / \mathrm{Aa}, 3$ to $\mathrm{A} / \mathrm{A}, 4$ to $\mathrm{BBB} / \mathrm{Bbb}, \ldots$ and 10 to $\mathrm{D} / \mathrm{C}$, Jump that is a variable equal to the number of notches between the prior rating and new rating and Speculative that is a dummy variable equal to one if the prior rating of the firm is on speculative level and zero otherwise.

We also consider in the model the sector in which the firm operates. Financial (Energy) is a dummy variable equal to one if the rating action involves Financial (OilEnergy) sector firms and zero otherwise.

To test if the financial turmoil has affected the informative content of rating events, we include in the model two variables. Financial crisis is a dummy variable equal to one if the event occurs after September, 152008 and zero otherwise. Volatility is the stock market volatility ${ }^{10}$ over stock issuer volatility in the event window.

\footnotetext{
${ }^{10}$ We compute the stock market volatility by estimating a $\operatorname{GARCH}(1,1)$ model for the Spanish stock market returns measured from the IBEX 35 index.
} 


\subsection{Probability of informative rating change}

In order to proxy the probability of informative rating event, we estimate the responses of stock risk and returns to rating actions. Following Abad and Robles (2014) we estimate the following model:

$$
R_{i t}=\alpha_{i}+\beta_{i} R_{m t}+\gamma_{s i} D_{s}+\lambda_{s i} D_{s t} R_{m t}+\varepsilon_{i t}
$$

where $R_{i t}$ is the return ${ }^{11}$ on stock $i$ at time $t$ from day -250 to day $+1(t=0$ is the announcement date); $R_{m t}$ is the return on the market index at time $t$, which we calculate using an equal weight index; $D_{s t}$ is a dummy variable taking on the value of one for the days in the event window $(-1,+1)$ and zero otherwise.

In expression (1), $\alpha_{i}$ is the average daily amount by which the stock outperforms the benchmark portfolio on days -250 through -1 and $\alpha_{i}+\gamma_{s i}$ is the average daily amount by which the stock outperforms the benchmark portfolio in the event window. Similarly, $\beta_{i}$ is the stock's beta with respect to the benchmark portfolio on days -250 through -1 and $\beta_{i}+\lambda_{s i}$ is the stock's beta with respect to the benchmark portfolio on days -1 through +1 . Finally, $\varepsilon_{i t}$ is an i.i.d. zero mean error term.

We can write the variance of returns according to model (1) as follows:

$$
\operatorname{var}\left(R_{i t}\right)=\delta_{i}^{2} \operatorname{var}\left(R_{m t}\right)+\operatorname{var}\left(\varepsilon_{i t}\right)
$$

where $\delta_{i}$ is $\beta_{i}+\lambda_{s i}$ in the event $(-1,+1)$ and $\beta_{i}$ on days -250 through -1 . Equation (2) shows the total risk of asset $i$ can be partitioned into two parts: the systematic

${ }^{11}$ Returns are computed as $R_{i t}=\operatorname{Ln}\left(\frac{P_{i t}+d_{i t}}{P_{i t-1}}\right) 100$, where $P_{i t}$ is the closing price of the stock $i$ on day $t$, corrected for stock splits, equity offerings and merger effects, and $d_{i t}$ is the dividend announced on day $t$. The source of data is the Spanish Electronic Continuous Stock Market. 
risk, $\delta_{i}^{2} \operatorname{var}\left(R_{m t}\right)$, which is a measure of how the asset covaries with the economy and the idiosyncratic risk, $\operatorname{var}\left(\varepsilon_{i t}\right)$, which is independent of the economy.

As Abad and Robles (2014) and Hubler et al. (2013) have shown, rating events can also impact on the idiosyncratic risk of the re-rated firm. We comprise this possibility by modeling $\operatorname{var}\left(\varepsilon_{i t}\right)$ in the return model (2) as a GJR-GARCH process as follows:

$$
\begin{aligned}
& \operatorname{var}\left(\varepsilon_{i t}\right)=h_{i t} \\
& h_{i t}=\omega_{0 i}+\sum_{q=1}^{Q} \omega_{1 i q} \varepsilon_{i t-q}^{2}+\sum_{p=1}^{P} \omega_{2 i p} h_{i t-p}+\sum_{q=1}^{Q} \omega_{3 i q} S_{t-p}^{-} \varepsilon_{i t-q}^{2}+\phi_{s i} D_{s t},
\end{aligned}
$$

where $D_{s t}$ is the event-window dummy defined above. If rating changes add new information about the idiosyncratic risk of the company, then $\phi_{s i} \neq 0$.

This model (expressions (2) to (4)) allows analyzing the effect of the announcement of credit rating on the stocks of the re-rated firm considering jointly the impact on expected returns and on the two components of risk (systematic and idiosyncratic). The hypothesis that a credit rating announcement conveys new information about the firm implies that $\gamma_{s i} \neq 0$ and/or $\lambda_{s i} \neq 0$ and/or $\phi_{s i} \neq 0$.

In order to compute and to test the significance of the responses of stock risks and returns $\left(\gamma_{s i}, \lambda_{s i}\right.$ and $\left.\phi_{s i}\right)$, the above model is estimated for each rating event in the sample. We apply the Quasi-Maximum Likelihood Estimator proposed by Bollerslev and Wooldridge (1992). QMLE gives generally consistent estimators that have an asymptotic normal distribution, and provides asymptotic standard errors robust to non-normality. 
From the estimation results, we classify each rating event as informative or noninformative according to the significance of the relevant parameters, $\gamma_{s i}, \lambda_{s i}$ and $\phi_{s i}$. For logit model, we define four dummy variables that proxy the informative content. With regards to the risk-return binomial, the first is equal to 1 if there are significant movements in risk-return binomial in the expected direction $\left(\gamma_{s i}, \lambda_{s i}\right.$ and $\phi_{s i}$ significantly different from zero) and equal to 0 otherwise. With regards to beta risk-return binomial, the second is equal to 1 if there are significant movements in beta and return in the expected direction $\left(\gamma_{s i}\right.$ and $\lambda_{s i}$ significantly different from zero) and equal to 0 otherwise. Finally, we consider separately the effects on systematic risk and on returns. The third dummy variable is equal to 1 if there is a significant movement in beta risk ( $\lambda_{s i}$ significantly different from zero) and equal to 0 otherwise, and the fourth is equal to 1 when there is a significant movement in returns $\left(\gamma_{s i}\right.$ significantly different from zero) and equal to 0 otherwise.

\section{Data and preliminary analysis}

We analyze three different rating actions: effective rating changes, rating reviews and outlook reports ${ }^{12}$ affecting the long-term debt of 38 firms listed in the

12 Rating agencies adds the debt of a firm to the watch list commonly after special events (e.g., changes in regulation, merger announcements, etc.), indicating a likely rating change within a short period of time. Outlooks indicate the creditworthiness trend in a medium-term timeframe. 
Spanish Stock Market from January 2000 to December $2010 .{ }^{13}$ We consider rating actions announced by Fitch, Moody's and Standard and Poor's. ${ }^{14}$

Taking into consideration the direction of the credit announcement, we group them into six different categories: effective upgrades, effective downgrades, review for upgrades, review for downgrades, and positive outlook reports and negative outlook reports. ${ }^{15}$ Previous information is used to distinguish between contaminated and uncontaminated rating events. Following Jorion and Zang (2007), a rating change is contaminated if any firm-specific event that may cause abnormal behavior, such as earning announcements, mergers and acquisitions or dividend payments, occurs during the 5 trading days around the announcement. The uncontaminated sample contains 292 rating actions, of which 201 are negatives and 91 are positives.

\section{[Insert Table 1]}

Table 1 presents the sample description. Panel A shows the distribution of rating actions per year and type (improvement/positive or deterioration/negative). The yearly number of negative rating changes increases during crisis periods: the dotcom bubble burst in 2001-2002 and the financial crisis in 2008-2009. The temporal

\footnotetext{
${ }^{13}$ This cover around $30 \%$ of firms in the Spanish Stock Market and the great majority are in the first quartile of capitalization.

${ }^{14}$ Fitch and Moody's provide us with their announcement dates. We also examine Reuters' publications and the economic press to find the rating announcement dates of S\&P and other additional information..

${ }^{15}$ Upgrades and downgrades are sometimes accompanied by other rating refinement (outlook changes and/or review process). We classify these multiple rating actions as effective rating changes excluding them from the outlook or review sample.
} 
behavior of upgrades is the opposite, with a notable reduction of the number of improvements in credit quality en the last three years. These patterns reflect the general deterioration in economic conditions.

Panel B presents the distribution by type of rating action and per agency. Moody's released $44.9 \%$ of the rating actions, Fitch released $28.1 \%$, and the remaining $27 \%$ were released by $\mathrm{S} \& \mathrm{P}$. We have 100 downgrades, 101 negative refinements (30 outlook reports and 71 watchlistings), 49 upgrades and 42 positive refinements (33 outlook reports and 9 watchlistings). Panel $\mathrm{C}$ shows the distribution according to the rating prior the announcement. The most of cases rating announcements affect firms in the investment grade. Finally, Panel D presents the number of rating actions by sector of the issuer. The majority of rating actions affect the financial sector (40.4\%). 12 of 33 firms in the sample are financial firms (mainly commercial banks and insurers). The energy sector accounts for the second-most rating changes (30.2\% of the total changes affecting 12 energy firms).

\section{Main results}

We report separately results for the baseline sample of deteriorations (Table 2) and for improvements (Table 3) in credit quality. We estimate four different binomial models in which the dichotomous variable that proxy the probability of occurrence of an informative rating action is computed considering if there are: (i) significant movements in return, systematic and idiosyncratic risk - Model 1 -; (ii) significant movements in returns and systematic risk - Model 2 -; (iii) significant movements in beta risk - Model 3 -; and (iv) significant movements in returns - Model 4-. For each 
model we show the parameter estimates jointly to the impact of significant explanatory variables on the marginal probability (AME).

Of the 199 deteriorations rating announcement in the sample, 28 (14.1\%) were informative rating action attending to binomial risk-return, 31 (15.6\%) attending to beta risk-return, $77(38.7 \%)$ attending to beta and 57 (28.6\%) attending to returns. On the other hand, of the 85 improvement rating announcement, $13(15.3 \%)$ were informative rating action attending to binomial risk-return and to beta risk-return, i.e. Model 1 and Model 2 have the same dichotomous variable pointing that if improvement announcements have informative contained about the risk, then they have for both risk, $24(28.2 \%)$ attending to beta and 21 (24.7\%) attending to returns.

\subsection{Results for deteriorations in credit quality}

Table 2 shows the estimated coefficients and the average marginal effects to analyze the attributes that affect the probability of informative deterioration announcements in the fourth estimated models. We report the McFadden pseudo-R2 statistic as a measure of goodness of the fit and the proportion of outcomes correctly predicted. Although the pseudo-R2 is relatively low, the overall percentage of events correctly predicted was relatively high. As can be seen, pseudo-R2 ranges from 0.08 (Model 4) to 0.14 (Model 2), suggesting the relative success of the estimated logit regression models in predicting the values of the dependent variable within the sample, whereas the proportion of outcomes correctly predicted ranges from $72 \%$ (Model 4 ) to $86 \%$ (Model 2).

[Insert Table 2] 
The first two columns of Table 2 report results for Model 1 . We do not find that the informative content of refinements be different than effective downgrades. The estimated coefficient for Review and Outlook report are not significant. As Altmant and Rijken (2007) state, these refinements transfer relevant information to the market, and we find that do it in the same way than effective rating changes. Moody's and $S \& P$ are not significant too, indicating that market do not find relevant differences in the information revealed by the three agencies in line to Guettler and Wahrenburg (2007) results.

The number CRAs that rate the issuer have a significant impact. Rating actions affecting issuers monitored by two agencies are less informative as Two agencies variable is negatively related to the probability of informative announcement. The marginal decrease in the probability is substantial (-0.13 points of probability). This result supports our hypothesis that higher level of monitoring increase visibility of firms and reduce the novel information contained by rating announcements. Our other proxy for the visibility of the firm (Highly and Barely covered variables) are not significant, pointing to no differences in the information content perceived by the market related to the frequency of rating actions of the issuer.

Surprisingly, the variables related to the agreement or disagreement among agencies (Simultaneous, Split-rating, and Second mover) are not significant. The probability of informative rating event seems to be not affected by whether this event presents the same opinion about the issuer default risk as the other agencies or not. Neither seems to be relevant to determine this probability that an announcement be include or break a solvency trend of the issuer. 
The likelihood of an informative announcement is related with the concept that agencies rated. We find that announcements of rating events affecting the issuer are more likely to enclose relevant information than those affecting the issues. As we expected, this downgrades related to deteriorations in the capability of issuers to pay its financial obligations, seems to disclose more relevant information than downgrades affecting specific debt issues. The change in the probability is 0.45 points when the announcement is about issuer. The announcement of a multiple rating event (i.e. affecting several concepts at time) does not impact on the probability that the event be informative.

We find evidence that the prior rating is a relevant attribute affecting the probability of informative events. We observe that for the higher rating level, $A A A / A a a$, this probability is lower than in the case of prior rating below it. The marginal change in probability decreases 0.12 points for these announcements. This result is in line to Jorion and Zhang (2007), pointing to weaker information effects for rating changes for high-rated firms related to low-rated firms. The activity of institutional investors, concentrated on the investment-grade level, could be behind this result. Regulation forces them to hold bonds rated in this market segment, making them especially concerned with debt that is next the investment/speculative frontier. Surprisingly, deteriorations affecting speculative debt do not seem to reveal differential information with respect to investment grade announcements.

As we expect, the number of notches the rating change affects positively the likelihood of existence of valuable information in the rating deterioration. The bigger the cut in rating level, the higher the probability of informative announcements. The 
average marginal effect is 0.10 point of probability, indicating that the jump size is relevant to explain this probability.

The activity sector of the re-rated firm is also an important attribute to determine the information content of rating events. Results indicate that when the rerated firm is a financial enterprise, usually banks, the likelihood of observing a significant response on the risk-return binomial is lower than for re-rated firms in other sectors. The magnitude of the partial derivatives is high, -0.13 points of probability. This evidence points to "too-big-to-fail" paradigm. This paradigm is especially adequate in the Spanish case, because the Spanish authorities had never allowed the default of any bank. ${ }^{16}$

Finally, although we would expect a relationship between the crisis and the informational content probability, we find that the both variables included to proxy crisis times (Financial crisis and Volatility) fail to explain the probability of informative rating deteriorations. This result indicates that negative announcements reveal relevant information in the same way before and after the crisis began.

As a whole, results for Model 1 indicate that negative issuer rating announcement that imply a big cut in the rating note significantly disclose higher levels information about returns and risks (systematic and idiosyncratic) of the rerated firms. Conversely, announcements affecting financial firms followed by two CRAs and

\footnotetext{
${ }^{16}$ In June 2009 Spanish government initiated a banking bailout and reconstruction program and created the Fund for Orderly Bank Restructuring, (FOBR). The Bank of Spain had intervened struggling lenders and FOBR had controlled mergers and acquisitions programs to rescue Spain's failing savings banks as Bankia in 2012.
} 
with the top rating level are probably the announcement with less relevant information to explain the risk-return binomial.

Results for Model 2, that analyze the probability of rating deteriorations containing information about the systematic risk-return binomial, are similar to those for Model 1. In this case, there are three additional attributes of the announcement that are relevant to explain this probability, i.e. that contain information about beta and returns, but no about idiosyncratic risk. Simultaneous announcements (those disclosed by two or more agencies the same day) signal to higher probability of informative rating event, being the marginal increase in this probability of 0.15 points. This result indicates that the consensus view of CRAs about deterioration in creditworthiness or a firm incorporates more information with regards beta and return to the market.

In line to our hypothesis, the likelihood of informative rating event is lower for downgrades included in a negative trend (i.e. several previous negative rating announcements). This result may reflect that the successive deterioration of firm creditworthiness increase the visibility of firm to market participants, who could anticipate the information before the release of the new rating level.

We also observe that downgrades preceded by a watch listing or review are less informative as Prior refinement variable has a negative impact on the probability of occurrence of informative events. This result confirms our hypothesis that expected events contains less novel information and it is contrary to Boot et al. (2006) statement. According to Altmant and Rijken (2007), the new information about the 
deterioration in the solvency of the firm was transferred to the market by the previous refinements.

Finally, Models 3 and 4 of Table 2 consider as dependent variable the probability of occurrence of an informative rating even measured as significant movements in the expected direction in beta risk (Model 3) and as significant movements in the expected direction in returns (Model 4).

In the case of beta risk, the number of significant attributes is lower than in the case of Model 1, 2 and 4. We find that only simultaneous negative announcements significantly disclose higher levels information about systematic risk whereas those affecting speculative-grade firms, followed by two CRAs, disclose lower levels of relevant information. Additionally, the announcement of deteriorations in credit quality seems to be less informative regarding beta after the Lehman Brothers' default. The loss of reputation of CRAs after the crisis began seems to have undermined the reliability of these announcements causing that market participants give agency actions less credibility.

In the case of Model 4, simultaneous announcement about issuer rating include relevant information to determine the returns, whereas announcements affecting top rated financial entities that show a continuous process of deterioration in their credit quality are less informative.

Remarkably, we find important differences between the main attributes that contain relevant information to explain the responses of beta risk to negative announcement and those that explain the responses of returns. In the latter case, 
factors as solvency trends, prior rating, the re-rated concept and the sector are relevant to determine the probability of informative content.

\subsection{Results for improvements in credit quality}

Table 3 reports the results for positive rating announcements. In this case we only estimate three models because, as we mention behind, Model 1 and 2 have the same endogenous variable. The pseudo-R2 statistic ranges from 0.33 to 0.43 , point to higher success of the estimated models than the deterioration models. As well as, the proportion of outcomes correctly predicted by the estimated models obtain from classification tables range from $81 \%$ to $89 \%$, which can be considered a fairly good result as deterioration models.

First two columns of Table 3 show the estimated coefficients and the average marginal effects to analyze the main attributes that affect the probability that an improvement contains relevant information about the risk-return binomial (Model 1). As in the case of deteriorations, and according with Altmant and Rijken (2007), rating refinements seems to transfer the same relevant information to the market than upgrades. Also in this case, our results do not indicate differences in the information revealed by the three agencies among agencies, in line to Guettler and Wahrenburg (2007).

\section{[Insert Table 3]}

Rating actions affecting issuers monitored by two agencies seems to contain less novelty information than other announcements because the Two agencies variable has a significant negative impact on the probability of informative event. The marginal 
decrease in this probability is -0.15 points of probability. According to this result, the higher the level of firm visibility, the lower the novel information contained by rating announcements. However, Highly and Barely covered variables are not significant.

Contrary to our hypothesis, the degree of agreement among agencies is not significant in Model 1. Additionally, we find that announcement included in a positive solvency trend of the issuer contains higher levels of relevant information about the risk-return binomial. The marginal increase in probability is 0.48 point. This result is the opposite to that we find for downgrades, indicating an asymmetric response of market to positive and negative news about the credit quality of a firm. This kind of asymmetries is commonly found in literature. ${ }^{17}$

The likelihood of an informative positive announcement is not related to the concept that agencies rated neither if rating has been preceded by a refinement. The prior rating affects the probability of informative improvements announcements. We observe that positive credit events affecting firms rated in levels A-BBB/Baa increase the likelihood of reveal novel information with respect to those affecting firms in the other levels. The marginal change in probability is 0.29 points. Regulation seems to force institutional investors to be more concerned with debt next the investment-grade frontier.

Our results point to a reputation effect. We find that the size of the jump in the rating note affects negatively the likelihood of existence of valuable information in the rating improvement. The average marginal decrease in probability is 0.25 points.

\footnotetext{
17 Ederington and Goh (1998), Hull, Predescu and White (2004) and Abad and Robles (2014).
} 
CRAs may delay the announcement of large improvements in the rating note of an issue or issuer. They may expend extra-time in the revision of the rating to avoid mistakes that can lead to a loss of reputation.

The likelihood to informative event is also affected by the activity sector of the re-rated firm, but in this case, the differential is detected for issuers belonging to the Energy sector. Announcements affecting oil-energy firms have a lower likelihood to cause a significant response on the risk-return binomial than those affecting firms in other sectors. The magnitude of the partial derivatives is high, -0.22 points of probability.

In the case of improvements, financial crisis affect the probability of informative rating events. We find that positive announcements dated after the Lehman Brothers' default have lower level of relevant information than announcements dated before pointing to the loss of reputation of CRAs after the crisis began.

Summarizing, results for the probability of occurrence of a rating improvement that contains relevant information about the risk-return binomial indicate that announcement affecting medium-lower rated firms that present a positive trend in solvency reveal higher levels of relevant information, whereas those announced before the crisis beginning, affecting energy firms, covered by two agencies, that imply a big improvement in the rating note reveal lower levels of novel information to the market.

Model 3 in Table 3 consider as dependent variable the probability of occurrence of a rating improvement that discloses relevant information to determine the systematic risk. The number of significant attributes is higher than those in Models 
1(2) and 4 and includes those detected in Model 1(2). In this case, announcements affecting highly covered firms in terms of the frequency of events and the number of CRAs include lower levels of relevant information whereas this level is higher for improvements announced simultaneously or by a second mover. In contrast to downgrades, in this case the presence of a prior refinement makes the upgrade more informative, according to Boot et al. (2006) hypothesis.

When we analyze the probability of occurrence of a positive announcement that reveals important information regarding returns (Model 4), we observe that those rating improvements disclosed by $\mathrm{S} \& \mathrm{P}$ are less informative with respect to the other agencies. In this case, the agreement among agencies does not influence the probability whereas if the improvement breaks a negative trend increases the level of relevant information.

\section{Conclusions}

The latest financial crisis has stressed the need of knowing the role that CRAs play in the financial system. This paper focuses on their function as information providers by analyzing the Informational Content Hypothesis of different credit rating actions announced by the three biggest global agencies in a sample of Spanish firms from 2000 to 2010. We analyze the joint reaction of the stock risk-return binomial to rating changes, previously unexplored.

We establish a wide set of hypothesis about the expected informative content of different types of announcements looking for the main features of the rating action, the 
agency, the re-rated firm and the economic environment to identify which rating events reveals more relevant information to determine the response of the risk-return binomial.

Some relevant insights emerge from the analysis. In line to the literature, we find important asymmetries between positive and negative announcement. The main attributes of informative rating actions are different depending on whether agencies announce an improvement in credit quality or whether they announce deterioration. We also find that the main attributes of rating events that are relevant to explain the response of systematic risk differs from those relevant to explain the response of returns.

Our results point to the existence of a loss of reputation of CRAs in the later financial turmoil, since we find that after the crisis beginning, positive and negative credit rating announcement disclose less relevant information.

We find that factors related to the existence of trends in the solvency of the firm (successive rating actions in the same direction), the presence of a prior refinement and the rating prior the announcement affect the probability of informative rating event positively in the case of improvements and negatively for deteriorations. The size of the movement in the rating note has the opposite impact, increasing the information content of downgrades and decreasing it for upgrades.

Conversely, for positive and negative announcement factors related to the visibility of the firm as the number of CRAs that rate the firms or if they operate in a strategic sector decrease the probability of informative events. Factors related to coincidence of opinion among agencies increase this probability. 
Finally, in the case of negative rating events, the announcement reveal more relevant information if it refers to the issuer, whereas for positive rating events the rated concept is not important. For positive events the releasing agency is relevant, being Standards and Poor's the less informative.

To conclude, we consider that those results are important because they can serve to identify the main features of the rating announcement relevant to understand the changes in the risk-return profile of the firm caused by the rating event, helping investors to improve their investment decisions. It is important to remark that we analyze the Spanish case, a medium-size European market, and is not possible to generalize our main conclusions. To do that it is necessary to provide more international in larger markets as the US or the Euro area. 


\section{References}

Abad, P., Robles, M.D. (2006), "Risk and returns around bond rating changes: new evidence from the Spanish stock market." Journal of Business, Finance and Accounting, 33(5) \& (6), 885-908

Abad, P., Robles, M.D. (2007), "Bond rating changes and stock returns: evidence from the Spanish stock market", Spanish Economic Review, 9, 79-103.

Abad, P., Robles, M.D. (2014), "Credit rating agencies and unsystematic risk: Is there a linkage? The Spanish evidence", International Review of Economics and Finance

Altman, E. I., Rijken, H. A. (2007), "The added value of Rating Outlooks and Rating Reviews to corporate bond ratings", Financial Management Association meeting, Barcelona.

Barron M.J., Clare A.D., Thomas S.H. (1997), "The effects of bond rating changes and new ratings on UK stocks returns", Journal of Business, Finance and Accounting, 24(3), 497-509.

Becker, B., Milbourn, T. (2011), "How did increased competition affect credit ratings?", Journal of Financial Economics, 101(3), 493-514.

Bollerslev, T., Wooldridge, J.M. (1992), "Quasi-Maximum Likelihood Estimation and Inference in Dynamic Models with Time-varying Covariances", Econometric Reviews 11, 143-172.

Bongaerts, D., Cremers, M., Goetzmann, W. (2012), "Tiebreaker: Certfication and multiple credit ratings", Journal of Finance, Volume 67(1), 113-152.

Boot, A.W.A., Milbourn, T.T., Schmeits, A. (2006), "Credit Ratings as Coordination Mechanisms", Review of Financial Studies, 19 (1), 81-118.

Cantor, R., Packer, F. (1997), "Differences of opinion and selection bias in the credit rating industry", Journal of Banking and Finance, 21(10), 1395-1417.

Chandra, U.; Nayar, N. (1998); "The Information Content of Commercial Paper Rating Downgrades: Further Evidence," Journal of Accounting, Auditing and Finance. 13(4), 417-435. 
Covitz, M., Harrison, P. (2003), "Testing conflicts of interest at bond ratings agencies with market anticipation: evidence that reputation incentives dominate," Federal Reserve Board, Finance and Economics Discussion Series 2003-68.

Ederington, L.H., Goh, J.C., (1998), "Bond Rating Agencies and Stock Analysts: Who Knows What When?", Journal of Financial and Quantitative Analysis, 33(4).

Elayan, F.A.; Hsu, W.H., Meyer, T.O., (2001), "The informational content of credit rating announcement for share prices in a small markets", Journal of Economics and Finance, 27, 337-356.

Grande, A., Parsley, D.C. (2005), "News spillovers in the sovereign debt market", Journal of Financial Economics, 75, 691-734.

Guettler, A., Wahrenburg, M., (2007), "The adjustment of credit ratings in advance of defaults", Journal of Banking and Finance, 31, 751-767.

Hubler, J., C. Louargant, J.N. Ory \& P. Raimbourg (2013), "Do rating agencies' decisions impact stock risks? Evidence from European markets", The European Journal of Finance, 1-29.

Hull, J., Predescu, M., White, A. (2004), "The Relationship between Credit Default Swap Spreads, Bond Yields, and Credit Rating Announcements", Journal of Banking and Finance, 28, 2789-2811.

Impson, C.M., Karafiath, I. and Glascock, J. (1992), "Testing Beta Stationarity across Bond Rating Changes", Financial Review, 27 (4), 607-618.

Jorion, P., Liu, Z., Shi, C. (2005), "Informational effects of regulation FD: evidence from rating agencies," Journal of Financial Economics, 76(2), 309-330.

Jorion, P., G. Zhang (2007), "Information Effects of Bond Rating Changes: The Role of the Rating Prior to the Announcement", Journal of Fixed Income, 16, 45-59.

Jewell, J., Livingston, M. (1999), “A comparison of bond ratings from Moody's, S\&P and Fitch IBCA", Financial Markets, Institutions and Instruments, 8, 1-45.

Livingston, M., Wei, J.D., Zhou, L. (2010), "Moody's and S\&P ratings: are they equivalent? Conservative ratings and split rated bond yields", Journal of Money, Credit and Banking, 42, 1267-1293 
Matolcy, Z. P., Lianto, T., (1995), "The incremental information content of bond rating revisions: The Australian evidence", Journal of Banking $\&$ Finance, 19(5), 891-902.

May, A. (2010), "The impact of bond rating changes on corporate bond prices: New evidence from the over-the-counter market," Journal of Banking and Finance, $34,2822-2836$

McFadden, D. 1974. "Conditional logit analysis of qualitative choice behavior". In Frontiers in Econometrics, ed. P. Zarembka, New York, Academic Press, 105142.

Morgan, D.P. (2002), "Rating Banks: Risk and Uncertainty in an Opaque Industry," American Economic Review, 92, 874-888.

Norden, L., Weber, M. (2004), "Informational efficiency of credit default swap and stock markets: The impact of credit rating announcements", Journal of Banking and Finance, 28, 2813-2843.

Peña-Cerezo, M.A., Rodríguez-Castellanos, A. Ibáñez-Hernández, F.J. (2013), "Multirating decision model validation: the relevance of the quality of securitization issues", Journal of Risk Model Validation, 7(3), 35-58.

Purda, L. D., (2007), "Stock market reaction to anticipated versus surprise rating changes", Journal of Financial Research, 30(2), 301-320.

Schweitzer, R., Szewczyk, S.H., Varma, R., (1992), "Bond rating agencies and their role in bank market discipline", Journal of Financial Services Research, 6(3), $249-263$

Weber, R., and Darbellay, A., 2008, The regulatory use of credit ratings in bank capital requirement regulations, Journal of Banking Regulation, Volume 10(1), $1-16$.

Xia, H. (2014), "Can investor-paid credit rating agencies improve the information quality of issuer-paid rating agencies?", Journal of Financial Economics, 111(2), 450-468. 
Table 1. Sample description

\begin{tabular}{lcccc}
\hline \multicolumn{5}{c}{ Panel A: Distribution per year } \\
\hline Year & Positives & Negatives & Total & \#Firms \\
\hline 2000 & 10 & 13 & 23 & 12 \\
2001 & 6 & 22 & 28 & 15 \\
2002 & 7 & 34 & 41 & 21 \\
2003 & 16 & 17 & 33 & 21 \\
2004 & 11 & 5 & 16 & 12 \\
2005 & 11 & 15 & 26 & 17 \\
2006 & 7 & 17 & 24 & 16 \\
2007 & 12 & 10 & 22 & 11 \\
2008 & 8 & 19 & 27 & 16 \\
2009 & 1 & 32 & 33 & 20 \\
2010 & 2 & 17 & 19 & 13 \\
\hline
\end{tabular}

Panel B: Distribution per rating action and agency

\begin{tabular}{lcccc}
\hline & Fitch & Moodys & S\&P & Total \\
\hline Downgrade & 37 & 38 & 25 & 100 \\
Neg. Outlook & 5 & 16 & 9 & 30 \\
Neg. Review & 20 & 32 & 19 & 71 \\
Upgrade & 11 & 24 & 14 & 49 \\
Pos. Outlook & 6 & 17 & 10 & 33 \\
Pos. Review & 3 & 4 & 2 & 9 \\
Total & $\mathbf{8 2}$ & $\mathbf{1 3 1}$ & $\mathbf{7 9}$ & $\mathbf{2 9 2}$ \\
\hline
\end{tabular}

Panel C: Distribution per prior rating

\begin{tabular}{lcccc} 
Rating & Positives & Negatives & Total & \#Firms \\
\hline AAA & & 12 & 12 & 9 \\
AA & 22 & 56 & 78 & 20 \\
A & 44 & 91 & 135 & 24 \\
BBB & 23 & 30 & 53 & 14 \\
BB & 1 & 6 & 7 & 4 \\
B & & 3 & 3 & 3 \\
CCC & & 1 & 1 & 1 \\
CC & & 2 & 2 & 1 \\
C & 1 & & 1 & 1 \\
\hline
\end{tabular}

\begin{tabular}{lcccccc} 
C & 1 & \multicolumn{1}{c}{1} & 1 \\
\hline \multicolumn{5}{c}{ Panel D: Distribution per sector } \\
\hline Sector & Positives & Negatives & Total & \#Firms \\
\hline Other & 12 & 65 & 77 & 9 & - \\
Oil and Energy & 20 & 77 & 97 & 12 & - \\
Financials & 59 & 59 & 118 & 12 & - \\
Total & $\mathbf{9 1}$ & $\mathbf{2 0 1}$ & $\mathbf{2 9 2}$ & $\mathbf{3 3}$ & - \\
\hline
\end{tabular}


Table 2. Determinants of ICH: deteriorations

\begin{tabular}{|c|c|c|c|c|c|c|c|c|}
\hline & \multicolumn{2}{|c|}{ Model 1} & \multicolumn{2}{|c|}{ Model 2} & \multicolumn{2}{|c|}{ Model 3} & \multicolumn{2}{|c|}{ Model 4} \\
\hline & Coef & $\mathrm{AME}$ & Coef & $\mathrm{AME}$ & Coef & $\mathrm{AME}$ & Coef & $\mathrm{AME}$ \\
\hline Review & 0.079 & - & -0.684 & - & -0.052 & - & -0.691 & - \\
\hline Outlook report & 0.637 & - & 0.081 & - & 0.371 & - & -0.519 & - \\
\hline Moody's & -0.639 & - & -0.422 & - & -0.337 & - & -0.249 & - \\
\hline$S E P$ & -0.470 & - & -0.084 & - & -0.490 & - & 0.025 & - \\
\hline Two aqencies & -1.523 & $-0.127 b$ & -1.280 & $-0.119 c$ & $-2.161 b$ & $-0.338 a$ & -0.396 & - \\
\hline Three aqencies & -1.214 & - & -1.255 & - & -1.455 & - & 0.122 & - \\
\hline Hiqhly covered & 0.869 & - & 0.689 & - & 0.349 & - & -0.151 & - \\
\hline Barely covered & 1.370 & - & 0.929 & - & 0.882 & - & 0.579 & - \\
\hline Simultaneous & 0.480 & - & $1.065 \mathrm{c}$ & 0.151 & $0.868 \mathrm{c}$ & $0.177 \mathrm{c}$ & $0.998 \mathrm{c}$ & $0.208 \mathrm{c}$ \\
\hline Split-ratinq & -0.077 & - & -0.101 & - & -0.284 & - & -0.423 & - \\
\hline Second mover & 0.029 & - & 0.470 & - & -0.144 & - & 0.297 & - \\
\hline Trend rating & -1.157 & - & -1.308 & $-0.118 c$ & 0.560 & - & -1.114 & $-0.176 c$ \\
\hline Break trend & 0.680 & - & 0.581 & - & -0.136 & - & -0.116 & - \\
\hline Prior refinement & -0.579 & - & -1.083 & $-0.106 c$ & 0.052 & - & -0.801 & - \\
\hline Multiple & -0.200 & - & -0.450 & - & -0.125 & - & -0.266 & - \\
\hline Issuer & $2.649 \mathrm{c}$ & 0.449 & 2.522 & - & 1.212 & - & $1.809 \mathrm{c}$ & $0.383 c$ \\
\hline$A A A / A a a$ & -1.856 & $-0.116 b$ & -1.821 & $-0.124 c$ & -1.269 & - & -1.574 & $-0.205 b$ \\
\hline$A A / A a$ & 0.060 & - & 0.284 & - & 0.183 & - & 0.157 & - \\
\hline$A-B B B / B a a$ & 0.357 & - & 0.364 & - & 0.575 & - & -0.096 & - \\
\hline Speculative & -0.699 & - & -0.585 & - & -1.306 & $-0.222 \mathrm{c}$ & 0.243 & - \\
\hline Jump & $0.933 \mathrm{~b}$ & $0.101 b$ & $0.782 \mathrm{c}$ & $0.089 \mathrm{c}$ & 0.456 & - & 0.457 & - \\
\hline Financial sector & $-1.582 \mathrm{c}$ & $-0.131 a$ & $-1.700 \mathrm{c}$ & $-0.149 a$ & -0.556 & - & -0.852 & $-0.143 c$ \\
\hline Financial crisis & 0.186 & - & 0.251 & - & -0.791 & $-0.156 c$ & 0.611 & - \\
\hline Volatility & -493.5 & - & -172.8 & - & -1011.4 & - & 1135.9 & - \\
\hline Constant & -1.039 & & -0.571 & & 1.105 & & -0.645 & \\
\hline$\%$ Accuarte & 86. & & 85 & & 66 & & 72 & \\
\hline Pseudo R2 & 0.1 & & 0.1 & & 0.1 & & & \\
\hline
\end{tabular}

Note: Sample from 01:2000 to 12:2010. a, b, c indicate significance at the $1 \%, 5 \%$ and 10\%, respectively. The dichotomous variable in Model 1 (Model 2) is regards to occurrence of an informative rating action in risk-return (beta-return) binomial. The dichotomous variable in Model 3 (Model 4) is regards to beta risk (return). AME is the average marginal effect. Review (Outlook reports) is a dummy variable equal to one if the rating action is a watchlisting (outlook review) and zero otherwise. Moody's $(\mathrm{S} \& \mathrm{P})$ is a dummy variable equal to one if the rating action is announced by Moody's (S\&P) and zero otherwise. Two (Three) agencies is a dummy variable that take the value of 1 if the issuer is rate by two (three) CRAs. Highly (barely) covered is a dummy variable equal to one if the issuer is in the first (fourth) quartile of issuer ranking regards to number of rating actions in the sample. Simultaneous is a dummy variable equal to one if the rating action has been announced by two or more agencies the same day and zero otherwise. Split-rating is a dummy variable equal to one if the rating action follows an action by other agency in the opposite direction in the preceding 3 months and zero otherwise. Second mover is a dummy variable equal to one if the rating action follows an action by other agency in the same direction in the preceding 24 months and zero otherwise. Trend rating is a dummy variable equal to one if the rating action has been preceded by one rating announcements in the same direction over the past 24 months and zero otherwise. Break trend is a dummy variable equal to one if the rating action has been preceded by two rating announcements in the opposite direction and zero otherwise. Prior refinement is a dummy variable equal to one if the rating action has been preceded by a watch listing or review and zero in otherwise. Multiple is a dummy variable equal to one if the rating action affects different kinds of debt. Issuer is a dummy variable equal to one if the rating events are related to issuer solvency and zero otherwise. Prior rating is encoding the rating categories of the previous rating of the issuer, assigning value 1 to AAA, 2 to AA, 3 to A, 4 to BBB, ... and 10 to D. Speculative is a dummy variable equal to one if the prior rating of the firm is from 5 to 10 and zero otherwise. Jump is a variable equal to the jump between the prior rating and new rating. Financial (Energy) Sector is a dummy variable equal to one if the rating action involves financial (oil) sector firms and zero otherwise. Financial crisis is a dummy variable equal to one if the event occurs after September, 152008 and zero otherwise. Volatility is a ratio between the volatility of the market and volatility of the issuer in the event window. 
Table 3. Determinants of ICH: improvements

\begin{tabular}{|c|c|c|c|c|c|c|}
\hline & \multicolumn{2}{|c|}{ Model 1 (2) } & \multicolumn{2}{|c|}{ Model 3} & \multicolumn{2}{|c|}{ Model 4} \\
\hline & Coef & AME & Coef & AME & Coef & AME \\
\hline Review & -3.106 & - & 0.231 & - & 0.255 & - \\
\hline Outlook report & -2.646 & - & 1.282 & - & -1.408 & - \\
\hline Moody's & 1.145 & - & 1.571 & - & 1.264 & - \\
\hline$S E P$ & -1.297 & - & -1.229 & - & -1.605 & $-0.167 \mathrm{c}$ \\
\hline Two agencies & -3.421 & $-0.153 c$ & -2.015 & - & -1.339 & - \\
\hline Three agencies & -18.902 & - & -2.728 & $-0.347 \mathrm{c}$ & -2.138 & $-0.269 c$ \\
\hline Highly covered & 12.967 & - & $-1.999 c$ & $-0.237 b$ & 0.346 & - \\
\hline Barely covered & -16.099 & - & -15.941 & - & -1.623 & - \\
\hline Simultaneous & 1.931 & - & $4.033 \mathrm{a}$ & $0.491 \mathrm{a}$ & 0.928 & - \\
\hline Second mover & 1.863 & - & $3.451 \mathrm{a}$ & $0.428 \mathrm{a}$ & 0.875 & - \\
\hline Trend rating & $5.419 \mathrm{~b}$ & $0.482 \mathrm{a}$ & $5.175 \mathrm{~b}$ & $0.540 \mathrm{a}$ & $3.822 \mathrm{~b}$ & $0.479 \mathrm{a}$ \\
\hline Break trend & 1.371 & - & 0.794 & - & $2.321 b$ & $0.301 b$ \\
\hline Prior refinement & 2.451 & - & $3.391 b$ & $0.379 \mathrm{a}$ & $2.325 \mathrm{c}$ & $0.276 \mathrm{c}$ \\
\hline Multiple & 0.700 & - & -0.796 & - & 0.835 & - \\
\hline$A A / A a$ & 1.227 & - & 1.322 & - & 0.517 & - \\
\hline$A-B B B / B a a$ & $3.697 \mathrm{~b}$ & $0.293 \mathrm{~b}$ & $3.143 \mathrm{~b}$ & $0.355 \mathrm{~b}$ & $2.516 \mathrm{c}$ & $0.289 \mathrm{c}$ \\
\hline Jump & -3.746 & $-0.251 b$ & -1.981 & $-0.213 c$ & -1.073 & - \\
\hline Energy sector & $-3.959 c$ & $-0.218^{\mathrm{a}}$ & $-2.905 b$ & $-0.272 \mathrm{a}$ & $-3.802 b$ & $-0.301 a$ \\
\hline Financial crisis & $-3.559 \mathrm{c}$ & $-0.161^{\mathrm{a}}$ & -1.794 & $-0.170 c$ & $-4.024 b$ & $-0.272 \mathrm{a}$ \\
\hline Volatility & 7.516 & - & 7.176 & - & 2.009 & - \\
\hline Constant & 4.039 & & 0.526 & & -0.322 & \\
\hline$\%$ Accuarte & \multicolumn{2}{|c|}{$89.4 \%$} & \multicolumn{2}{|c|}{$84.7 \%$} & \multicolumn{2}{|c|}{$81.2 \%$} \\
\hline Pseudo R2 & \multicolumn{2}{|c|}{0.429} & \multicolumn{2}{|c|}{0.402} & \multicolumn{2}{|c|}{0.338} \\
\hline
\end{tabular}

See note Table 2 